\title{
The Role of Low-Level Laser Therapy in the Treatment of Multiple Sclerosis: A Review Study
}

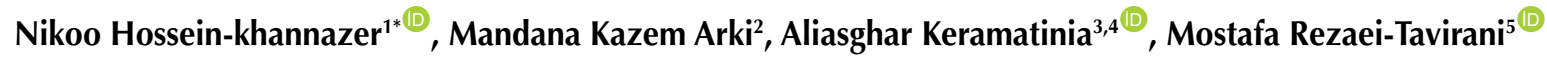 \\ ${ }^{1}$ Laser Application in Medical Sciences Research Center, Shahid Beheshti University of Medical Sciences, Tehran, Iran \\ ${ }^{2}$ Gastroenterology and Liver Diseases Research Center, Research Institute for Gastroenterology and Liver Diseases, \\ Shahid Beheshti University of Medical Sciences, Tehran, Iran \\ ${ }^{3}$ Department of Social Medicine, School of Medicine, Shahid Beheshti University of Medical Sciences, Tehran, Iran \\ ${ }^{4}$ Cancer Research Center, Shahid Beheshti University of Medical Sciences, Tehran, Iran \\ ${ }^{5}$ Proteomics Research Center, Faculty of Paramedical Sciences, Shahid Beheshti University of Medical Sciences, \\ Tehran, Iran
}

\section{*Correspondence to Nikoo Hossein-Khannazer, Email: nikookhannazer@gmail. com}

Received: October 14, 2021 Accepted: December 25, 2021 Published online December 28 2021

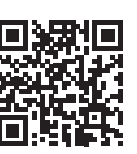

\begin{abstract}
Introduction: Multiple sclerosis (MS) is an autoimmune disease. Inflammatory cells, cytokines and chemokines play a major role in the pathogenesis of the disease. Low-level laser therapy (LLLT) as a photobiostimulation approach could affect a wide range of cellular responses. LLLT inhibits the inflammatory signaling pathway, improves cell viability, inhibits apoptosis, modulates immune responses and induces the production of growth factors.

Methods: In this review, we discuss the effect of LLLT on cellular responses and its application in the treatment of MS. Such keywords as "low-level laser therapy", "photobiomodulation" and "multiple sclerosis" were used to find studies related to laser therapy in MS in Google scholar, PubMed and Medline databases.

Results: LLLT reduced the inflammatory immune cells and mediators. It also enhanced the regeneration of neurons.

Conclusion: Investigations showed that besides current treatment strategies, LLLT could be a promising therapeutic approach for the treatment of MS.

Keywords: Low-level laser therapy (LLLT), Multiple sclerosis (MS), Photobiomodulation, Laser therapy, Autoimmune disease
\end{abstract}

\section{Introduction}

Multiple sclerosis (MS) is a central nervous system (CNS) autoimmune disease, characterized by chronic inflammation, demyelination of the white matter and finally axon loss. Although the exact etiology of the MS disease is not fully understood, genetic predisposition and environmental conditions are some of the contributed etiological factors. Dysregulation of the immune system plays a major role in the pathology of the MS disease. ${ }^{1,2}$ Chronic inflammation which occurs in MS disease activates innate and adaptive immune responses. ${ }^{2}$ The prolonged production of the inflammatory cytokines and chemokines could activate autoreactive immune responses against CNS antigens and cause the loss of selftolerance. Immune cells such as macrophages, dendritic cells (DCs) and T helper (TH) cell subsets (TH1, TH17, TH22) cause excessive inflammation and CNS tissue injury.-5 Current treatment strategies, including antiinflammatory and immunosuppressive treatments, have limited benefits, especially in the progressive stage of the disease. ${ }^{1}$ It seems that new treatment options are needed in order to control the inflammation and prevent the demyelination of the CNS. ${ }^{6,7}$ Laser immunotherapy as a photo-thermal approach is focused on the photoimmunomodulation properties of the lasers which could regulate the immune responses in various autoimmune disorders and cancers. ${ }^{8}$ In this review, we focused on the effects of low-level laser therapy (LLLT) on the cellular responses and also immunomodulatory effects of LLLT on immune responses in the MS disease as a binary treatment approach.

\section{Inflammatory Responses in the Pathogenesis of MS}

Inflammatory responses play a crucial role in the pathogenesis of MS. Autoreactive $\mathrm{CD}^{+} \mathrm{T}$ cell subsets, including TH1, TH17, and TH22, against myelin antigens, have a pivotal role in autoimmune responses. ${ }^{9}$ These cells produce a large number of inflammatory cytokines such as interleukin 1 beta (IL-1 $\beta$ ), interferon gamma (IFN- $\gamma$ ), interleukin-17 (IL-17A), IL-17F, interleukin 23 (IL23) and interleukin 22 (IL-22). ${ }^{10-12}$ Recently, it has been shown that besides T CD4 cells, T CD 8 cells and B cells 
and macrophages play a major role in the pathogenesis of $\mathrm{MS}^{13}$ Moreover, the function of the regulatory $\mathrm{T}$ cell subsets (CD4+CD25+ Treg) which produce antiinflammatory cytokines like interleukin 10 (IL-10) and transforming growth factor beta (TGF- $\beta$ ) is impaired. It has also been indicated that $\mathrm{T}$ reg cells migration, survival and cytokine production decreased during the MS inflammatory responses. ${ }^{14,15}$

\section{Low-Level Laser Effects on Cell Biology}

LLLT consists of non-thermal red or near infrared light (600-1000 nm) which might affect many cellular processes, including mitochondrial activity, cell proliferation, differentiation, cell death, production of adenosine triphosphate (ATP), synthesis of DNA, and so on. ${ }^{16,17}$ Due to the beneficial effects of LLLT, it is widely used as a treatment approach in a variety of diseases. ${ }^{18-21}$ One of the important effects of laser radiation is the inhibition of apoptosis and regulating cell viability. ${ }^{22}$ It was shown that low-power laser radiation caused the sharp expression of the B-cell lymphoma 2 (Bcl-2) antiapoptotic gene. ${ }^{23}$ Moreover, it could markedly inhibit the BCL2-Associated X Protein (BAX) proapoptotic gene. Laser radiation also induced cell cycle progression and proliferation. ${ }^{24,25}$

Low-power laser radiation suppressed the inflammatory responses and at the same time stimulated anti-oxidant activity. ${ }^{26,27}$ It was revealed that laser radiation inhibited nuclear factor kappa B (NF- $\mathrm{B})$, the key inflammatory transcription factor, and the related signaling pathways like inflammatory cytokines. ${ }^{28,29}$ LLLT also reduced oxidative stress by inhibiting the production of reactive oxygen species (ROS) and inducible form of nitric oxide synthase (iNOS) expression in oxidatively-stressed cells. ${ }^{24,29-31}$

Moreover, low-level laser radiation enhanced the production and release of various small molecules and growth factors, including TGF- $\beta$, brain-derived neurotrophic factor (BDNF), platelet-derived growth factor, and glial-derived neurotrophic factor. ${ }^{32-34}$

In regenerative medicine, besides the secretion of the growth factors, inhibiting the inflammatory microenvironment is crucial. As mentioned above, LLLT could attenuate the inflammatory conditions and has the ability to increase the production of various growth factors. Such properties make this physical, non-invasive strategy a promising tool in regenerative medicine. ${ }^{16}$

\section{Effect of the Laser on the Central Nervous System}

LLLT is widely used in neurological conditions, including degenerative brain disease, stroke, traumatic brain injury, and spinal cord injury. ${ }^{35-38}$ LLLT could stimulate neuron regeneration and induce the proliferation of Schwann cells. ${ }^{39}$ LLLT also increased the BDNF which is a crucial growth factor for neuronal survival and growth. It was shown that LLL had beneficial effects on Alzheimer's disease through the inhibition of $A \beta$-induced neurotoxicity and neurons loss. ${ }^{40,41}$ Moreover, it was reported that laser therapy boosted nerve conduction.

Investigations indicated that the post-stroke LLLT approach improved brain injury and neurons function. ${ }^{42,43}$ LLLT significantly influenced brain lesions and induced the generation of new neurons in stroke-induced rats. LLLT inhibited neuron apoptosis and enhanced neurons viability. LLLT also increased BDNF in brain injuries. ${ }^{43-45}$ This treatment approach was also approved in the rabbit embolic stroke model. ${ }^{42}$ It seems that LLLT has beneficial effects on ischemic tissues.

Low-power laser irradiation induced peripheral nerve injuries. ${ }^{46}$ It was also reported that laser irradiation augmented sciatic nerve injury and inhibited spinal cord neurons degeneration. ${ }^{47,48}$ Moreover, it was shown that combination therapy using LLLT $(660 \mathrm{~nm})$ and chondroitinase ABC enzyme had more beneficial effects on the functional recovery of the spinal cord injury than each treatment alone. ${ }^{49} \mathrm{~A}$ recent in vitro study also indicated a novel mechanism by which LLLT could decrease excitotoxicity which contributed to neurodegenerative disorders and brain trauma. ${ }^{50-52}$ It was revealed that LLLT photons were absorbed into the cytochrome c, increased ATP production, and decreased NO and oxidative stress in the lesions. ${ }^{30}$ Thus, LLLT preserved and altered excitotoxicity in cultured cortical neurons. ${ }^{53}$

\section{Low-Level Laser Therapy in the Treatment of MS}

It was indicated that laser therapy is a promising approach for numerous diseases. ${ }^{54,55}$ Previous studies indicated that LLLT had beneficial effects in controlling inflammation and induced tissue repair. It was indicated that LLLT possessed modulating properties and could reduce brain inflammation. ${ }^{56}$ Laser photobiomodulation protected the cells and tissues from inflammatory mediators. ${ }^{57}$ Elaine et al indicated that the LLLT strategy (AlGaInP LLLT (660 nm) and GaAs LLLT (904 nm)) could reduce the severity of the disease in the C57BL/6 experimental autoimmune encephalomyelitis (EAE) model. LLLT could significantly $(P<0.001)$ postpone the onset of the disease manifestations. LLLT caused the inhibition of the weight loss and mortality of the animals and reversed the weight loss process. ${ }^{58} \mathrm{NO}$ contributed to most of the neurodegenerative disorders like MS. ${ }^{59} \mathrm{NO}$ is highly expressed in MS lesions and is an indicator of macrophages and microglia activation and disease progression. ${ }^{60}$ Elaine et al showed that LLLT reduced the amount of NO in the brain, spinal cord and spleen compared to the EAE control group. Another aspect of the LLLT strategy is the inhibition of immune cell trafficking. LLLT could markedly slow down the infiltration of the lymphocytes into the CNS and also limit the injured 
demyelinated parts. Using LLLT also had a great impact on inflammatory cytokines including IL-17, IL- $1 \beta$ and IFN- $\gamma$. In this manner, LLLT reduced the expression of mentioned cytokines ${ }^{58}$ (Figure 1).

Recently, due to the promising results of laser therapy in various diseases, the application of laser biostimulation has been investigated in 120 MS patients. The study showed that laser therapy could significantly improve the Expanded Disability Status Scale (EDSS) index of the patients and highly refine the patients' physical condition. In addition, laser radiation improved MS patients' quality of life. It was also reported that the combination of laser therapy and low-frequency magnetic stimulation could augment the beneficial effects. ${ }^{61}$

Interestingly, another randomized clinical trial on 14 MS patients showed that photobiomodulation (wavelength: $808 \mathrm{~nm}$; power output: $100 \mathrm{~mW}$ ) successfully induced the expression of the serum IL10 anti-inflammatory cytokine in the MS patient with no statistical difference in nitrites levels. ${ }^{62}$ It was also reported that LLLT had a great impact on optic nerve improvement in MS individuals. ${ }^{63}$

Mesenchymal stem cells (MSCs) are multipotent stem cells and have great immunomodulatory properties and differentiation abilities. ${ }^{464-66}$ These cells have been used

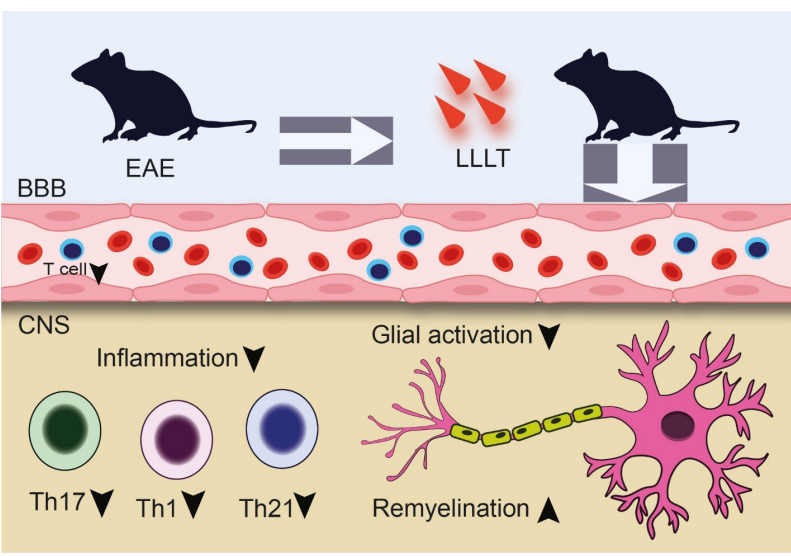

Figure 1. LLLT anti-inflammatory effects on the EAE animal model. LLLT reduced the inflammatory cells and mediators and inhibited inflammation and neuronal loss. Moreover, LLLT caused remyelination in neurons. Low-level laser therapy (LLLT), blood brain barrier (BBB), experimental autoimmune encephalomyelitis (EAE), $\mathrm{T}$ helper $(\mathrm{TH})$. as a therapeutic modality in a wide range of diseases, including MS. ${ }^{67}$ MSCs therapy reduced the inflammation and stimulated re-myelination of the neurons. ${ }^{68,69} \mathrm{~A}$ recent study indicated that pre-treated cells with LLLT before injection had better viability and proliferation rate. Treated cells also induced myelin formation. ${ }^{70}$ Combination therapy using human adipose-derived stem cells and laser irradiation on spinal cord injury showed that such a treatment approach enhanced the improvement of motor function. ${ }^{44}$ It was also shown that LLLT induced epidermal growth factor (EGF) secretion from MSCs, which leads to better in vitro maintenance of $\mathrm{MSCs}^{71}$ (Table 1)

Altogether, it seems that laser therapy could add to the rehabilitation and physiotherapy regime of MS patients.

\section{Discussion}

Developments in LLLT devices make them a promising therapeutic approach for the treatment of various diseases. Several studies have indicated that LLLT had immunomodulatory effects on biological processes. LLLT reduced inflammation, decreased immune cell trafficking and downregulated inflammatory cytokine secretion. In vitro and in vivo studies also showed that the LLLT could modulate the regeneration of neurons and had beneficial effects on the improvement of MS manifestations. It also delayed the onset of the disease in animal models. Clinical studies revealed that LLLT inhibited inflammatory responses in MS patients and improved patients' physical conditions. It seems that LLLT through these mechanisms could be an additional treatment option for the treatment of MS and other neurodegenerative disorders.

\section{Conclusion}

LLLT leads to a reduction in inflammatory immune cells, including TH1 and TH17, inhibits inflammation, and augments brain tissue regeneration. Although studies indicated that LLLT modulated the inflammatory cascades and immune cells, the mechanisms of action of such a treatment strategy are unclear. Future investigations need to clarify the exact mechanism of LLLT on immunomodulation.

Table 1. Animal model and clinical trial studies of LLLT on MS

\begin{tabular}{|c|c|c|c|}
\hline Year & Study & Intervention & Result \\
\hline 2016 & $\begin{array}{l}\text { Experimental autoimmune } \\
\text { encephalomyelitis (EAE), }\end{array}$ & LLLT (AlGalnP, $660 \mathrm{~nm}$ and GaAs, $904 \mathrm{~nm}$ ) & $\begin{array}{l}\text { Reduced the clinical score, delayed disease onset, down- } \\
\text { regulated NO }\end{array}$ \\
\hline 2016 & 120 MS patients & $\begin{array}{l}\text { Wavelengths } 650 \mathrm{~nm} \text { and of power } 50 \mathrm{~mW} \text { generated by } \\
\text { the device TERAPUS }\end{array}$ & Improved the functional status of patients \\
\hline 2019 & Canine model of MS & MSC treated with LLLT & Increased remyelination, prevented the scar formation \\
\hline 2018 & C57BL/6 mice & $\operatorname{LLLT}\left(36 \mathrm{~J} / \mathrm{cm}^{2}, 50 \mathrm{~mW}, 0.028 \mathrm{~cm}^{2}\right.$ spot area) & Improved motor performance, attenuated demyelination \\
\hline 2019 & 19 MS patients & LLLT & Induced pain relief \\
\hline 2020 & 14 MS patients & Wavelength of $808 \mathrm{~nm}$, output power of $100 \mathrm{~mW}$ & Increased the level of IL-10, unchanged nitrite levels \\
\hline
\end{tabular}




\section{Conflict of Interests}

The authors declare no conflict of interest.

\section{Ethical Considerations}

Not applicable.

\section{References}

1. Dargahi N, Katsara M, Tselios T, Androutsou M-E, De Courten M, Matsoukas J, et al. Multiple Sclerosis: Immunopathology and Treatment Update. Brain Sci. 2017;7(7):78. doi:10.3390/brainsci7070078

2. Grigoriadis N, Van Pesch V. A basic overview of multiple sclerosis immunopathology. Eur J Neurol. 2015;22 Suppl 2:3-13. doi:10.1111/ene. 12798

3. Lassmann $\mathrm{H}$, Brück $\mathrm{W}$, Lucchinetti CF. The immunopathology of multiple sclerosis: an overview. Brain Pathol. 2007;17(2):210-218. doi:10.1111/j.17503639.2007.00064.x

4. Hashemi SM, Hassan ZM, Hossein-Khannazer N, Pourfathollah AA, Soudi S. Investigating the route of administration and efficacy of adipose tissue-derived mesenchymal stem cells and conditioned medium in type 1 diabetic mice. Inflammopharmacology. 2020;28(2):585601. doi:10.1007/s10787-019-00661-x

5. Hossein-khannazer N, Shabani S, Farokhfar M, Azizi G, Asarzadegan F, Safarpour Lima B, et al. Pivotal cytokines and their transcription factors are the targets of guluronic acid (G2013) for inhibiting the immunopathogenesis process of multiple sclerosis. Drug Dev Res. 2020;81(4):511516. doi:10.1002/ddr.21645

6. Huang WJ, Chen WW, Zhang X. Multiple sclerosis: Pathology, diagnosis and treatments. Exp Ther Med. 2017;13(6):3163-3166. doi:10.3892/etm.2017.4410

7. Torkildsen $\varnothing$, Myhr KM, Bø L. Disease-modifying treatments for multiple sclerosis - a review of approved medications. Eur J Neurol. 2016;23 Suppl 1(Suppl 1):18-27. doi:10.1111/ene.12883

8. Chen WR, Liu H, Ritchey JW, Bartels KE, Lucroy MD, Nordquist RE. Effect of different components of laser immunotherapy in treatment of metastatic tumors in rats. Cancer Res. 2002;62(15):4295-4299.

9. Hemmer B, Archelos JJ, Hartung H-P. New concepts in the immunopathogenesis of multiple sclerosis. Nat Rev Neurosci. 2002;3(4):291-301. doi:10.1038/nrn784

10. Comabella M, Khoury SJ. Clin Immunol. 2012;142(1):2-8. doi:10.1016/j.clim.2011.03.004

11. Hossein-Khannazer N, Zian Z, Bakkach J, Kamali AN, Hosseinzadeh R, Anka AU, et al. Features and roles of T helper 22 cells in immunological diseases and malignancies. Scand J Immunol. 2021; 93:e13030. doi:10.1111/sji.13030

12. Prat E, Martin R. The immunopathogenesis of multiple sclerosis. J Rehabil Res Dev. 2002;39(2):187-199.

13. Yadav SK, Mindur JE, Ito K, Dhib-Jalbut S. Curr Opin Neurol. 2015;28(3):206-219. doi:10.1097/WCO.0000000000000205

14. Haas J, Fritzsching B, Trübswetter P, Korporal M, Milkova L, Fritz B, et al. Prevalence of newly generated naive regulatory $\mathrm{T}$ cells (Treg) is critical for Treg suppressive function and determines Treg dysfunction in multiple sclerosis. J Immunol. 2007;179(2):1322-1330. doi:10.4049/ jimmunol.179.2.1322

15. Venken $\mathrm{K}$, Hellings $\mathrm{N}$, Broekmans $\mathrm{T}$, Hensen $\mathrm{K}$, Rummens J-L, Stinissen P. Natural naive CD4+ CD25+ CD127low regulatory $\mathrm{T}$ cell (Treg) development and function are disturbed in multiple sclerosis patients: recovery of memory Treg homeostasis during disease progression. J Immunol. 2008;180(9):6411-6420. doi:10.4049/jimmunol.180.9.6411

16. Abrahamse H. Regenerative medicine, stem cells, and lowlevel laser therapy: future directives. Photomed Laser Surg. 2012;30(12):681-682. doi:10.1089/pho.2012.9881

17. Chung H, Dai T, Sharma SK, Huang Y-Y, Carroll JD, Hamblin MR. The nuts and bolts of low-level laser (light) therapy. Ann Biomed Eng. 2012;40(2):516-533. doi:10.1007/ s10439-011-0454-7

18. Strübing I, Gröschel M, Schwitzer S, Ernst A, Fröhlich F, Jiang D, et al. Neuroprotective Effect of Near-Infrared Light in an Animal Model of CI Surgery. Audiol Neurootol. 2021;26(2):95-101. doi:10.1159/000508619

19. Xu Z, Guo X, Yang Y, Tucker D, Lu Y, Xin N, et al. Low-level laser irradiation improves depression-like behaviors in mice. Mol Neurobiol. 2017;54(6):4551-4559. doi:10.1007/ s12035-016-9983-2

20. Oron A, Oron U. Low-level laser therapy to the bone marrow ameliorates neurodegenerative disease progression in a mouse model of Alzheimer's disease: a minireview. Photomed Laser Surg. 2016;34(12):627-630. doi:10.1089/ pho.2015.4072

21. Mokmeli S, Vetrici M. Low level laser therapy as a modality to attenuate cytokine storm at multiple levels, enhance recovery, and reduce the use of ventilators in COVID-19. Can J Respir Ther. 2020;56:25-31.doi:10.29390/cjrt-2020015

22. Yun Y-C, Jang D, Yoon S-B, Kim D, Choi D-H, Kwon O, et al. Laser acupuncture exerts neuroprotective effects via regulation of $\mathrm{Creb}, \mathrm{Bdnf}, \mathrm{Bcl}-2$, and Bax gene expressions in the hippocampus. Evid Based Complement Alternat Med. 2017;2017:7181637. doi:10.1155/2017/7181637

23. Zhang C, Hao T, Chen P, Liang J, Wang C, Kang H, et al. Effect of low level laser irradiation on the proliferation of myoblasts-the skeletal muscle precursor cells: an experimental in vitro study. Laser Phys. 2011;21(12):21227. doi:10.1134/S1054660X11210328

24. Gao X, Xing D. Molecular mechanisms of cell proliferation induced by low power laser irradiation. J Biomed Sci. 2009;16(1):4. Published 2009 Jan 12. doi:10.1186/14230127-16-4

25. Torres S, De Sanctis J, de Briceno L, Hernandez N, Finol $\mathrm{H}$. Inflammation and nitric oxide production in skeletal muscle of type 2 diabetic patients. J Endocrinol. 2004;181(3):419-427. doi:10.1677/joe.0.1810419

26. Aimbire F, Santos F, Albertini R, Castro-Faria-Neto H, Mittmann J, Pacheco-Soares C. Low-level laser therapy decreases levels of lung neutrophils anti-apoptotic factors by a NF- $\kappa$ B dependent mechanism. Int Immunopharmacol. 2008;8(4):603-605. doi:10.1016/j.intimp.2007.12.007

27. Avni D, Levkovitz S, Maltz L, Oron U. Protection of skeletal muscles from ischemic injury: low-level laser therapy increases antioxidant activity. Photomed Laser Surg. 2005;23(3):273-277. doi:10.1089/pho.2005.23.273

28. Shefer G, Partridge TA, Heslop L, Gross JG, Oron U, Halevy O. Low-energy laser irradiation promotes the survival and cell cycle entry of skeletal muscle satellite cells. J Cell Sci. 2002;115(Pt 7):1461-1469.

29. Rizzi CF, Mauriz JL, Freitas Corrêa DS, Moreira AJ, Zettler CG, Filippin LI, et al. Effects of low-level laser therapy (LLLT) on the nuclear factor (NF)- $\mathrm{kB}$ signaling pathway in traumatized muscle. Lasers Surg Med. 2006;38(7):704-713. 
doi:10.1002/lsm.20371

30. Huang YY, Nagata K, Tedford CE, McCarthy T, Hamblin MR. Low-level laser therapy (LLLT) reduces oxidative stress in primary cortical neurons in vitro. $J$ Biophotonics. 2013;6(10):829-838. doi:10.1002/jbio.201200157

31. Ojaghi R, Sohanaki H, Ghasemi T, Keshavarz F, Yousefifard M, Sadeghipour H. Role of low-intensity laser therapy on naloxone-precipitated morphine withdrawal signs in mice: is nitric oxide a possible candidate mediator? Lasers Med Sci. 2014;29(5):1655-1659. doi:10.1007/s10103-014-1530-7

32. Byrnes KR, Wu X, Waynant RW, Ilev IK, Anders JJ. Low power laser irradiation alters gene expression of olfactory ensheathing cells in vitro. Lasers Surg Med. 2005;37(2):161171. doi:10.1002/lsm.20202

33. Yu W, Naim JO, Lanzafame RJ. The effect of laser irradiation on the release of bFGF from $3 \mathrm{~T} 3$ fibroblasts. Photochem Photobiol. 1994;59(2):167-170. doi:10.1111/j.1751-1097.1994.tb05017.x

34. Leung MC, Lo SC, Siu FK, So KF. Treatment of experimentally induced transient cerebral ischemia with low energy laser inhibits nitric oxide synthase activity and up-regulates the expression of transforming growth factorbeta 1. Lasers Surg Med. 2002;31(4):283-288. doi:10.1002/ lsm.10096

35. Thunshelle C, Hamblin MR. Transcranial low-level laser (light) therapy for brain injury. Photomed Laser Surg. 2016;34(12):587-598. doi:10.1089/pho.2015.4051

36. Hashmi JT, Huang YY, Osmani BZ, Sharma SK, Naeser MA, Hamblin MR. PM R. 2010;2(12 Suppl 2):S292-S305. doi:10.1016/j.pmrj.2010.10.013

37. Mansouri V, Razzaghi M, Rostami-Nejad M, RezaeiTavirani M, Heidari MH, Safari S, et al. Neuroprotective properties of photobiomodulation in retinal regeneration in rats: perspectives from interaction levels. J Lasers Med Sci. 2020;11(3):280-286. doi:10.34172/jlms.2020.47

38. Blivet G, Meunier J, Roman FJ, Touchon J. Neuroprotective effect of a new photobiomodulation technique against $\mathrm{A} \beta_{25-35}$ peptide-induced toxicity in mice: Novel hypothesis for therapeutic approach of Alzheimer's disease suggested. Alzheimers Dement (N Y). 2018;4:54-63. doi:10.1016/j. trci.2017.12.003

39. Rojas JC, Lee J, John JM, Gonzalez-Lima F. Neuroprotective effects of near-infrared light in an in vivo model of mitochondrial optic neuropathy. J Neurosci. 2008;28(50):13511-13521. doi:10.1523/ JNEUROSCI.3457-08.2008

40. Meng C, He Z, Xing D. Low-level laser therapy rescues dendrite atrophy via upregulating BDNF expression: implications for Alzheimer's disease. J Neurosci. 2013;33(33):13505-13517. doi:10.1523/ JNEUROSCI.0918-13.2013

41. Guerriero F, Sgarlata C, Francis M, Maurizi N, Faragli A, Perna S, et al. Neuroinflammation, immune system and Alzheimer disease: searching for the missing link. Aging Clin Exp Res. 2017;29(5):821-831. doi:10.1007/s40520-0160637-z

42. Lapchak PA, De Taboada L. Transcranial near infrared laser treatment (NILT) increases cortical adenosine-5'triphosphate (ATP) content following embolic strokes in rabbits. Brain Res. 2010;1306:100-5. doi:10.1016/j. brainres.2009.10.022

43. Oron A, Oron U, Chen J, Eilam A, Zhang C, Sadeh M, et al. Low-level laser therapy applied transcranially to rats after induction of stroke significantly reduces long-term neurological deficits. Stroke. 2006;37(10):2620-2624. doi:10.1161/01.STR.0000242775.14642.b8

44. Sarveazad A, Janzadeh A, Taheripak G, Dameni S, Yousefifard M, Nasirinezhad F. Co-administration of human adipose-derived stem cells and low-level laser to alleviate neuropathic pain after experimental spinal cord injury. Stem Cell Res Ther. 2019;10(1):1-15. doi: 10.1186/ s13287-019-1269-y.

45. Kim J, Kim E-H, Lee K, Kim B, Kim Y, Na SH, et al. Lowlevel laser irradiation improves motor recovery after contusive spinal cord injury in rats. Tissue Eng Regen Med. 2017;14(1):57-64. doi:10.1007/s13770-016-0003-4

46. Rochkind S. Stimulation effect of laser energy on the regeneration of traumatically injured peripheral nerves. Morphogen Regen. 1978;83:25-7.

47. Rochkind S, Nissan M, Alon M, Shamir M, Salame K. Effects of laser irradiation on the spinal cord for the regeneration of crushed peripheral nerve in rats. Lasers Surg Med. 2001;28(3):216-219. doi:10.1002/lsm.1041

48. Rochkind S, Barrnea L, Razon N, Bartal A, Schwartz M. Stimulatory effect of He-Ne low dose laser on injured sciatic nerves of rats. Neurosurgery. 1987;20(6):843-847. doi:10.1227/00006123-198706000-00004

49. Janzadeh A, Sarveazad A, Yousefifard M, Dameni S, Samani FS, Mokhtarian K, et al. Combine effect of Chondroitinase $\mathrm{ABC}$ and low level laser $(660 \mathrm{~nm})$ on spinal cord injury model in adult male rats. Neuropeptides. 2017;65:90-99. doi:10.1016/j.npep.2017.06.002

50. McGeer E, McGeer P. Neurotoxins as tools in neurobiology. Int Rev Neurobiol. 1981;22:173-204.

51. Yu T, Yu H, Zhang B, Wang D, Li B, Zhu J, et al. Promising neuroprotective function for M2 microglia in Kainic Acid-induced neurotoxicity via the down-regulation of NF- $\mathrm{KB}$ and caspase 3 signaling pathways. Neuroscience. 2019;406:86-96. doi:10.1016/j.neuroscience.2019.03.002

52. Janzadeh A, Nasirinezhad F, Masoumipoor M, Jameie SB. Photobiomodulation therapy reduces apoptotic factors and increases glutathione levels in a neuropathic pain model. Lasers Med Sci. 2016;31(9):1863-1869. doi:10.1007/s10103016-2062-0

53. Huang YY, Nagata K, Tedford CE, Hamblin* MR. Lowlevel laser therapy $(810 \mathrm{~nm})$ protects primary cortical neurons against excitotoxicity in vitro. $J$ Biophotonics. 2014;7(8):656-664. doi:10.1002/jbio.201300125

54. Rykała J, Szychta P, Witmanowski H. Physical and biological bases of laser phototherapy. Advances in Dermatology \& Allergology/Postepy Dermatologii i Alergologii. 2012;29(5): 378-383.

55. Lan C-CE, Wu S-B, Wu C-S, Shen Y-C, Chiang T-Y, Wei Y-H, et al. Induction of primitive pigment cell differentiation by visible light (helium-neon laser): a photoacceptor-specific response not replicable by UVB irradiation. J Mol Med (Berl). 2012;90(3):321-330. doi:10.1007/s00109-011-0822-

56. Liang J, Liu L, Xing D. Photobiomodulation by lowpower laser irradiation attenuates $A \beta$-induced cell apoptosis through the Akt/GSK3 $\beta / \beta$-catenin pathway. Free Radic Biol Med. 2012;53(7):1459-1467. doi:10.1016/j. freeradbiomed.2012.08.003

57. Lavi R, Shainberg A, Friedmann H, Shneyvays V, Rickover $\mathrm{O}$, Eichler $\mathrm{M}$, et al. Low energy visible light induces reactive oxygen species generation and stimulates an increase 
of intracellular calcium concentration in cardiac cells. $J$ Biol Chem. 2003;278(42):40917-40922. doi:10.1074/jbc. M303034200

58. Gonçalves ED, Souza PS, Lieberknecht V, Fidelis GS, Barbosa RI, Silveira PC, et al. Low-level laser therapy ameliorates disease progression in a mouse model of multiple sclerosis. Autoimmunity. 2016;49(2):132-142. doi: 10.3109/08916934.2015.1124425

59. Acar G, Idiman F, Idiman E, Kırkalı G, Çakmakçı H, Özakbaş S. Nitric oxide as an activity marker in multiple sclerosis. J Neurol. 2003;250(5):588-592. doi:10.1007/ s00415-003-1041-0

60. Giovannoni G, Heales SJ, Land J, Thompson E. The potential role of nitric oxide in multiple sclerosis. Mult Scler. 1998;4(3):212-216. doi:10.1177/135245859800400323

61. Kubsik A, Klimkiewicz R, Janczewska K, Klimkiewicz P, Jankowska A, Woldańska-Okońska M. Application of laser radiation and magnetostimulation in therapy of patients with multiple sclerosis. NeuroRehabilitation. 2016;38(2):183-190. doi:10.3233/NRE-161309

62. Silva T, Fragoso YD, Destro Rodrigues MFS, Gomes AO, da Silva FC, Andreo L, et al. Effects of photobiomodulation on interleukin-10 and nitrites in individuals with relapsingremitting multiple sclerosis-Randomized clinical trial. PLoS One. 2020;15(4):e0230551. doi:10.1371/journal. pone. 0230551

63. Essa SA, Mostafa YM, Fathi SM, Elhafez HM, Ahmed AF, El Fayoumy N. Could Phototherapy Reverse Visual Deficits in Patients with Relapsing-Remitting Multiple Sclerosis? J Med Sci Clin Res. 2015;3(5):5479-94.

64. Uccelli A, Laroni A, Freedman MS. Mesenchymal stem cells as treatment for MS-progress to date. Mult Scler. 2013;19(5):515-519. doi:10.1177/1352458512464686

65. Xiao J, Yang R, Biswas S, Qin X, Zhang M, Deng W.
Mesenchymal stem cells and induced pluripotent stem cells as therapies for multiple sclerosis. Int J Mol Sci. 2015;16(5):9283-9302. Published 2015 Apr 24. doi:10.3390/ ijms16059283

66. Hossein-Khannazer N, Hashemi SM, Namaki S, Ghanbarian H, Sattari M, Khojasteh A. Study of the immunomodulatory effects of osteogenic differentiated human dental pulp stem cells. Life Sci. 2019;216:111-118. doi:10.1016/j.lfs.2018.11.040

67. Gharibi T, Ahmadi M, Seyfizadeh N, Jadidi-Niaragh F, Yousefi M. Immunomodulatory characteristics of mesenchymal stem cells and their role in the treatment of multiple sclerosis. Cell Immunol. 2015;293(2):113-121. doi:10.1016/j.cellimm.2015.01.002

68. Mohyeddin Bonab M, Ali Sahraian M, Aghsaie A, Ahmadi Karvigh S, Massoud Hosseinian S, Nikbin B, et al. Autologous mesenchymal stem cell therapy in progressive multiple sclerosis: an open label study. Curr Stem Cell Res Ther. 2012;7(6):407-414. doi:10.2174/1574888812804484648

69. Meamar R, Nematollahi S, Dehghani L, Mirmosayyeb $\mathrm{O}$, Shayegannejad V, Basiri K, et al. The role of stem cell therapy in multiple sclerosis: An overview of the current status of the clinical studies. Adv Biomed Res. 2016;5:46. doi:10.4103/2277-9175.178791

70. Abdallah AN, Shamaa AA, El-Tookhy OS. Evaluation of treatment of experimentally induced canine model of multiple sclerosis using laser activated non-expanded adipose derived stem cells. Res Vet Sci. 2019;125:71-81. doi:10.1016/j.rvsc.2019.05.016

71. Mvula B, Moore T, Abrahamse H. Effect of low-level laser irradiation and epidermal growth factor on adult human adipose-derived stem cells. Lasers Med Sci. 2010;25(1):3339. doi:10.1007/s10103-008-0636-1 